\title{
EDUARDO LOURENÇO E A TERCEIRA MARGEM DO \\ Brasil: um olhar Português sobre o Sertão
}

\section{Eduardo Lourenço and the third Brazilian margin: a Portuguese eye over the Backland}

\author{
Edna da Silva Polese* \\ Jaqueline Koehler $^{* *}$
}

\begin{abstract}
RESUMO
O olhar português sobre o Brasil incita nosso imaginário, seja sobre questões iluminadoras ou ressentidas entre as duas nações. Vários ensaios de Eduardo Lourenço na obra $A$ nau de Ícaro debruçam-se sobre essas questões. Dentre essas, a leitura de "Guimarães Rosa e o terceiro sertão" proporciona esse olhar do crítico português inicialmente sobre um momento considerado fundamental para a independência de nossa literatura: a semana de Arte Moderna de 1922. Adiante, relaciona

* Professora Adjunta 1 do Departamento Acadêmico de Linguagem e Comunicação (DALIC) da Universidade Tecnológica Federal do Paraná (UTFPR/Câmpus Curitiba). Doutora em Letras - Estudos Literários pela Universidade Federal do Paraná - UFPR.

** Doutoranda em Estudos Literários pela UFPR. Professora de literatura nas Faculdades
\end{abstract} Integradas Santa Cruz. 
esse acontecimento a obras fundamentais que focam o espaço conhecido como sertão, misto de espaço físico e construção imaginária-simbólica. Será na obra de Guimarães Rosa que essa construção será conduzida à hora zero, termo do utilizado pelo crítico para anunciar a importância da obra roseana.

Palavras-chave: Eduardo Lourenço, A nau de Ícaro, Guimarães Rosa.

\begin{abstract}
The Portuguese look at Brazil incites our imagination about even illuminating or resentful issues between both nations. Several essays written by Eduardo Lourenço in his work Icarus Ship (A nau de Ícaro) discuss these issues. Among these, the reading of "Guimarães Rosa and the third Backland" ("Guimarães Rosa e o terceiro sertão") gives us the Portuguese critical look firstly about a special moment to the independence of our literature: The Week of Modern Art, 1922. Later, this event is related to the fundamental works that focus on a space known as backland, a mixture of physical space and imaginary-symbolic construction. It's in Guimarães Rosa's work that this construction will be conducted to what we call "zero time" - the term is used by the critic to show the importance of Rosa's work.
\end{abstract}

Keywords: Eduardo Lourenço, Icarus Ship, Guimarães Rosa.

\title{
1. UMA BREVE LEITURA SOBRE NOSSA FORMAÇÃO LITERÁRIA
}

Eduardo Lourenço inicia o ensaio "Guimarães Rosa e o terceiro sertão" tecendo um comentário acerca do que ele chama ser um dos mitos de fundação da cultura brasileira, a Semana de Arte Moderna de 1922. Declara não comungar inteiramente com a ideia de mito que cerca o acontecimento, mas percebe ali uma das grandes posturas intelectuais do Brasil: o de se confirmar como nação com cultura e identidade própria, principalmente em relação a uma língua que se diferenciava de maneira peculiar daquela de origem europeia. Em ensaios anteriores ${ }^{1}$, Eduardo Lourenço destaca a busca

de Ícaro.

1 Estamos sempre nos referindo à ordem como estão disponibilizados na obra $A$ nau 
do Brasil pela identidade e a necessidade, como ele chama, de "matar o pai": "Para o discurso cultural brasileiro, Portugal existe pouco ou nada, mas se existe, é apreendido como o pai colonizador que o Brasil teve de matar para poder existir."2

Essa questão começa a se destacar no período romântico quando a cultura e a literatura brasileira, seguindo a tendência europeia, tentam firmar sua identidade criando um Brasil sonhado, idealizado. Era encenado um palco que se abria para o maravilhoso e o exótico, a natureza deslumbrante e grandiosa:

O Brasil, além da terra de sonho, foi sempre um continente sonhado, não tendo ainda deixada de o ser na atualidade. Durante um século, os seus filhos, já responsáveis por um país independente, sonharam-lhe a história, a literatura, a sociologia, a própria geografia de um espaço que só pode ser descrito com um dos atributos de Deus, o da imensidade. Levando a cabo essa tarefa, José de Alencar, Capistrano, Varnhagen, Silvio Romero criaram a identidade brasileira sob um modelo que não era muito diverso na Europa, onde povos de velha história se revisitavam para fazer boa figura na era de um nacionalismo e de um imperialismo que chegaria até nós. (LOURENÇO, 2001, p. 208-209)

O registro de Eduardo Lourenço faz lembrar dois grandes teóricos com visões muito diferentes acerca do momento em que se dá essa ruptura: por um lado, Antonio Candido com o Formação da Literatura Brasileira, em que percebe uma progressão mais estabilizada a partir do Arcadismo, terminando no momento exato em que Machado de Assis entra em cena; e por outro lado, a opinião de Afrânio Coutinho em Conceito de literatura brasileira, no qual afirma o início da identidade brasileira quando o europeu pisou nessas terras:

Esse processo não podia deixar de modificar profundamente o homem criando um novo homem, sob todos os aspectos. Como considerá-lo, pois um simples continuador do europeu? Não; como afirmou Ortega y Gasset, um homem novo criou-se desde o primeiro instante em que pôs o pé no novo mundo. Foi o americano, o brasileiro. A sua fala, sua sensibilidade, suas emoções, sua poesia, sua música, tinham de ser, e foram, diferentes, diferenciadas desde o início. Nada tem em comum com o que se produziu na Europa. (COUTINHO, 2008, p. 15) 
Afrânio Coutinho destaca como os intelectuais do período romântico - o romancista José de Alencar e os críticos Araripe Junior, Sílvio Romero e José Veríssimo - preocupavam-se em enxergar um divisor de águas, que estabelecesse esse momento de divórcio. Já havia uma postura bastante atuante nesse sentido e Araripe Junior criou o termo "obnubilação" para provar que desde os primeiros séculos o homem europeu que aqui chegou deparou-se com outra natureza e situação; nesse momento, passa a diferenciar-se do europeu. À medida que adentrava o Brasil, essa diferenciação tornou mais evidente esse processo, criando um novo homem e, portanto, uma nova literatura.

Vale aqui registrar a sugestão de Afrânio Coutinho para a mudança do título Formação da literatura brasileira, de Antonio Candido, para Autonomia da literatura brasileira, visto que, segundo Coutinho, a literatura já estava formada:

Tem razão Antonio Candido, portanto, em afirmar que não é uma literatura orgânica funcionando como sistema coerente a que existiu antes do Arcadismo. Mas não se pode negar que já uma literatura, que já se "formara", que não "vivia", mas "já existia". Assim o seu livro deveria denominar-se "autonomia da literatura brasileira”, e não "formação". Formação deu-se na época barroca e os padrões barrocos então vigentes, e que deram os fundamentos à nossa consciência, foram tão importantes na época a ponto de plasmá-la, que ainda hoje repercutem em nossa alma e em nossa vida de maneira profunda. Constituem muito mais vivências em nós do que os arcádicos neoclássicos. (COUTINHO, 2008, p. 57)

Antonio Candido anuncia no seu Formação que o seu intuito é perceber quando a Literatura se constrói e toma consciência de si:

Embora reconheça a importância da noção de período, utilizei-a aqui incidentemente atendendo à evidência estética e histórica, sem preocupar-me com distinções rigorosas. Isso, porque o intuito foi sugerir, tanto quanto possível, a ideia de movimento, passagem, comunicação - entre fases, grupos e obras; sugerir uma certa labilidade que permitisse ao leitor sentir, por exemplo, que a separação evidente, do ponto de vista estético, entre as fases neoclássica e romântica, é contrabalançada, do ponto de vista histórico, pela sua unidade profunda. À diferença entre estas fases, procuro somar a ideia da sua continuidade, no sentido da tomada de consciência literária e tentativa de construir uma literatura. (CANDIDO, 2012, p. 38) 
Candido percebe nos momentos neoclássicos e românticos uma unidade literária, perceptível no contrabalanço entre produção, tema e língua. Há uma consciência evidente que permeia não somente a produção literária em si, mas também o momento histórico em que está embasada.

Esse entrecruzamento de vozes entre Lourenço, Coutinho e Candido nos direciona para uma questão que faz parte dos debates sobre literatura no Brasil: esses tais momentos primordiais, fundadores. A obra de Antonio Candido estabelece um ponto de chegada com a construção literária de Machado de Assis. Mais do que imprimir um novo modo de narrar, pensando-se aqui em narrativas como Memórias Póstumas de Brás Cubas, é na linguagem que a arte do Bruxo do Cosme Velho irá principalmente sobrepor-se. A fina ironia, marca registrada de Machado, constrói-se a partir de um domínio da língua até então obediente demais aos padrões estabelecidos. Para Candido, isso se dá principalmente com o ensaio "Instinto de Nacionalidade", em que Machado de Assis percebe esse "desejo de criar uma literatura mais independente". (MACHADO, 1873, p. 2). Machado critica a forte tendência de se cantar a cor local, como o tema do indianismo, vastamente trabalhado tanto em formas romanescas como poéticas:

Não há dúvida que uma literatura, sobretudo uma literatura nascente, deve principalmente alimentar-se dos assuntos que lhe oferece a sua região, mas não estabeleçamos doutrinas tão absolutas que a empobreçam. O que se deve exigir do escritor antes de tudo, é certo sentimento íntimo, que o torne homem do seu tempo e do seu país, ainda quando trate de assuntos remotos no tempo e no espaço. (MACHADO DE ASSIS, 1873, p. 3)

Ainda nesse texto, Machado define o que deve ser o tema literário: tudo o que possa ser imaginado, não se restringindo a temas pré-estabelecidos como a natureza vigorosa e a construção da imagem do herói mítico. Assim, ele analisa como a forma romanesca obedece ainda a critérios bastante delimitados, demonstrando uma falta de amadurecimento em relação aos temas e aprofundamento filosófico, por exemplo:

Esta casta de obras conserva-se aqui no puro domínio de imaginação, desinteressada dos problemas do dia e do século, alheia às crises sociais e filosóficas. Seus principais elementos são, como disse, a pintura dos costumes, e luta das paixões, os quadros da natureza, alguma vez o estudo dos sentimentos e dos caracteres; com esses elementos, que são fecundíssimos, possuímos já uma galeria numerosa e a muitos respeitos notável. (MACHADO DE ASSIS, 1873, p. 5) 
No decorrer do ensaio, Machado de Assis tece comentários sobre a produção poética e teatral, marcando os defeitos e as qualidades dessas produções até o momento. Termina o texto chamando atenção exatamente para a língua: o quanto é precioso perceber que a mudança é natural, que não há por que exigir que a boa literatura se expresse ao molde dos anos de 1500 , nem há que se aceitar que o escritor absorva todas as novidades da língua, principalmente as citadinas, para estabelecer os critérios da escrita. Cabe ao talento e à postura desse escritor perceber o uso e a sensibilidade de uma nova literatura, que se expressa agora de uma maneira diferente de suas origens europeias.

Fazendo esse percurso, não é de se estranhar que Os sertões, publicado em 1902, tenha causado um impacto tão profundo quanto ao tema, que é uma espécie de registro de cor local grotesca, e quanto à linguagem, pois há a dificuldade em se entranhar na escrita de Euclides da Cunha ${ }^{3}$. Esse baque será sentido com a publicação de Os sertóes: descobre-se uma espécie humana resistente e forte, mas longe dos ideais românticos que estabeleceriam o mito fundador ou ainda o homem esclarecido, filho dos ventos Iluministas europeus. A resistência vem de um chão duro e de uma realidade que beira o grotesco. É com esse representante autêntico de brasilidade que a crítica, a cultura e o país terão que lidar.

Walnice Nogueira Galvão (2009) aponta para o fato de Euclides, ao direcionar seu olhar para o interior do país, descrever e estudar a constituição étnica brasileira e tentar compreender as idiossincrasias das mazelas por que passa o país, acaba por dialogar com a postura dos nossos modernistas:

(...) o Modernismo vai dar continuidade a algumas das preocupaçóes de Euclides com os interiores do país e com a repulsa à macaqueação europeia nos focos populacionais litorâneos. Partilha igualmente com ele a reflexão sobre a especificidade das condições históricas do país, na medida em que já em Os sertões Euclides realizara um mapeamento de temas que se tornarão centrais na produção intelectual e artística do século XX, ao debruçar-se sobre o negro, o índio, os pobres, os sertanejos, a condição colonizada, a religiosidade popular, as insurreições, o subdesenvolvimento e a dependência. Aí fincam suas raízes não só o Modernismo mas

3 Walnice Nogueira Galvão, no artigo "Polifonia e Paixão" (2009), afirma o quanto parece estranho pensar que Euclides escreve no mesmo período que Machado: "Parece pouco plausível, mas Euclides da Cunha está escrevendo Os sertóes na contemporaneidade do grande romance realista de Machado de Assis, que marca a maturidade deste e seus últimos anos de vida." (p. XXV). 
também o romance regionalista de 1930 e o nascimento das ciências sociais no país na década de 40. (GALVÃo, p. XXVI)

Como se percebe, a crítica especializada vem se ocupando dessas questões de maneira dinâmica. Há momentos em que essa busca pelo momento fundador debruça-se sobre produções e temas; outros em que se destaca a atitude intelectual, como é o caso da semana de 1922. Identidade e presença nacional aliadas à língua (que, aos poucos, molda-se a novos contornos) figuram como embasamento dessas produções e momentos.

Quando se fala de Os sertóes e Grande sertão: veredas incita-se o mesmo tipo de discussão, pelo menos no sentido de identidade (no caso de Os sertões) e língua (no caso de Grande sertão: veredas). Fato é que a crítica especializada sempre discute sobre os momentos cruciais em que a independência cultural e literária se estabilizou. De forma mais específica, Lourenço, no ensaio em questão, analisa esse espaço conhecido como sertão e como se estabelece, de acordo com a sua leitura, a diferenciação entre $o$ que ele considera três momentos primordiais.

\section{Os SERTÕEs de EduARdo LoUREnço}

Valendo-se do momento histórico conhecido como a Semana de 1922 e traçando um paralelo com o surgimento da obra de Euclides da Cunha, Eduardo Lourenço debruça esse olhar português percebendo a necessidade e ânsia do Brasil em estabelecer uma identidade cultural própria e finalmente deslocada do pai fundador, Portugal. Para o crítico, a semana que marca o momento cultural passou a ser lida como um marco, mas não como um mito. O movimento trouxe a ideia da antropofagia e seus idealizadores, com isso, teriam colocado o Brasil numa espécie de hora zero da literatura. Lourenço estabelece que a língua, afinal, vai direcionar os momentos primordiais em que uma literatura se posiciona. Assim, esclarece que para os portugueses a obra de Euclides da Cunha não é tão conhecida. É ainda um texto fechado em que a grandiosidade do espaço desconhecido e de seu povo perduram. A maior contribuição é que a obra de Euclides colocou em contraste dois mundos que compartilhavam o mesmo continente: o do homem citadino e litorâneo, que busca modernizar-se aos moldes europeus; e um homem sertanejo, desconhecido e principalmente esquecido:

Os sertões, de Euclides da Cunha, não é uma obra desconhecida dos leitores portugueses - mas tampouco lhe é familiar - aquela 
espécie de "pedra de Rosetta" da literatura e do imaginário brasileiros que ficou - e penso que aí está - na sua paisagem cultural como uma enigmática e obtusa pedra no caminho. Em Os sertóes, o Brasil brasileiro descobre-se como terra, como humanidade, como sociedade, como história sem miragens - em suma, como uma espécie de anti-retrato da "terra maravilhosa" que nenhum desmentido da ordem da história ou da natureza jamais apagarão. Aquele Brasil de Euclides - nome predestinado de geômetra - parece uma invenção do Sem Nome, como dirá aquele que um dia transfiguraria essa realidade dantesca em palco para novelas de cavalaria e ficções ao divino. O que Euclides da Cunha revela a um país todo ele voltado em sonhos para uma qualquer Europa como é ainda o dos primeiros coronéis-jagunços de Jorge Amado-, mas também para uma literatura que já percorrera com Machado de Assis os labirintos do coração e da vida, foi, simplesmente, o sertão. Não apenas aquelas paisagens lunares, inóspitas, inférteis - até infernais, - onde os homens se alinham pela urgência das águas e das raízes secas da restinga, terras do interior baiano ou cenário das nada míticas Vidas Secas, mas sobretudo a sua essência de mundo desolado e inumano, quer dizer, o Brasil como sertão. (LOURENÇO, 2001, p. 210)

Lourenço percebe o impacto causado por Os sertões - que, de certa forma, destrói os sonhos de modernidade dos centros urbanos que buscavam voz e sofisticação, frente a uma imagem dantesca produzida pela escrita de Euclides ao testemunhar a Campanha de Canudos. Do fundo do Brasil, do interior ainda inacessível surgia o homem brasileiro que o Brasil moderno não queria ver, mas que foi obrigado. Daí surge a expressão de Lourenço: o primeiro sertão - aquele visto por Euclides, aquele minuciosamente descrito em sua obra, que revela o autêntico brasileiro.

(...) independentemente da sua genealogia e indiferente a ela, o homem que aquela terra fizera, moldara, vaqueiro, nômada, contemplativo, guerreiro por sua conta ou de quem o servia, em suma, o homem de um outro Brasil que na óptica apaixonada e profética de Euclides era, mesmo sob a sua condição miserável e o estigma da degeneração (termo então muito na moda segundo a antropologia européia que tanto influenciou), o brasileiro autêntico.(LOURENÇO, 2001, p. 211)

Segundo Lourenço, com Os sertões não se começou a vera história do povo brasileiro, "mas revelou-se a insignificância e o termo da sua pseudo- 
-história, a qual nem fora capaz de assumir realmente a continuidade de um viver de mais de três séculos num mundo novo, nem de romper com ela, integrando com originalidade o seu novo destino de continente obcecado pelo futuro." (2001, p. 211). O "relógio sem ponteiros do sertão" provoca a revolução modernista. A visão de Euclides sobre o sertão cumpre a função de um mito. Walnice Nogueira Galvão, como já apontado, estabelece também essa relação. Os sertões se apresenta como um texto cuja visão de mundo é um tanto quanto datada, e que constantemente revela o descompasso do que é Canudos, já que pretende com sua obra denunciar o crime cometido pelo Estado; paralelamente, apresenta juízos de valor negativos em relação aos sertanejos, e por isso acaba por sintetizar uma ideia de Brasil. Mesmo que longe da proposta modernista em relação ao modo como utiliza a linguagem, Euclides desvela ao Brasil sua essência, como propagarão os intelectuais de 22.

Após a análise desse primeiro sertão, caminha-se para o registro de um segundo sertão, o qual está concentrado no chamado romance regionalista. O termo, assim como as designações "literatura do Nordeste", "literatura de Minas", "literatura do Sul", parece desagradar Eduardo Lourenço, que prefere remeter-se às obras célebres de Graciliano Ramos, José Lins do Rego, Jorge Amado e Raquel de Queiroz. Esse sertão é o espaço de uma humanidade sem futuro, perdida numa espécie de fantasmagoria da fome e do desespero, na guerra de seus fundadores e na violência assumida, aquém da lei, seja humana ou divina. Não há espaço para a salvação. Dirige-se para um futuro improvável.

Nessas obras (como as de Graciliano Ramos, José Lins do Rego e Jorge Amado), Lourenço aponta como característica comum a presença da violência e de uma história brasileira que precisa ser denunciada, mas que se fixa no plano da ideologia. São textos que possuem histórias que são "contra-Histórias" do nosso país e que, talvez justamente por isso, conseguiram exportar essa visão do Brasil como algo exótico. Como a arte produzida no calor dos acontecimentos da Semana de 22, esse segundo sertão parece fazer parte de um projeto literário construído artificialmente, com vistas a denunciar; o olhar português o identifica como "épicos às avessas".

O palco da história do Brasil (OS sertóes) e a contra-História do Brasil (romance de 30, romance regionalista) transfiguram-se num segundo sertão. Nesse cenário, Lourenço aponta para mais uma mudança de perspectiva em relação ao olhar destinado à história brasileira, em que haverá uma transfiguração dos dois primeiros sertões a um terceiro sertão nos textos de João Guimarães Rosa: 
Sob a verdade dos dois sertões, nunca negada, antes revisitada numa reverberação sem fim, a da singularidade cósmica, a da fatalidade telúrica, com a sua guerra social sem solução, o autor de Sagarana, de Corpo de baile e de Grande sertão: veredas descobre a universalidade de um combate, indissociavelmente terrestre e celeste, que tem como centro cada ser humano e como teatro, o Sertão, assimilado ao mundo inteiro. (LOURENÇO, 2001, p. 214)

Assim, subjaz a esse discurso a visão do paraíso, as sagas guerreiras, a figura dos heróis de cavalaria para configurar uma ordem cósmica universal. Riobaldo atravessa toda história para descobrir que "o amor é realmente a essência do universo" (2001, p. 216).

Só pelo caminho que não há (aquele que tomamos, contudo, como o único que existe) - o da dor, da morte, do erro, do ódio, sobretudo o ofuscante da mentira, a própria essência do diabo - é que nos é acessível a escarpada ascensão até aos limites que não podem ser os de Deus, mas sim do sonho com que o exigimos para que o mundo não seja mera alegoria do inferno.(LOURENÇO, 2001, p. 216)

Eduardo Lourenço percebe esse grande embate do homem brasileiro que se configura na imagem dos personagens do Grande sertão. Mais adiante, observa que a obra ocuparia o seu lugar de destaque na literatura mundial mesmo que estivesse submetida a ser o que ele chama de "colossal remake neomedieval" e "neobarroco temperado":

Se o Grande sertão fosse apenas um colossal remake neomedieval e neobarroco temperado com rituais linguageiros joyceanos, já não seria pouco. Como livro do sertão metafísico ou místico, teria o seu lugar na imensa revelação-revisitação do imaginário ficcional de todas as épocas, o qual era ou é o anúncio de um tempo literário como o nosso, que sabia que estava batendo no muro (ou no fundo do mar) da modernidade. (LOURENÇO, 2001, 218)

No entanto, isso tudo ainda não é o que o livro anuncia, pois a língua em comum é a busca final, o cerne que dá conta da universalidade da obra:

Todavia, é esse extraordinário anacronismo que instala o imaginário brasileiro na terceira margem de si mesmo - a que sempre 
foi e permanecia, se não invisível, superficialmente explorada. Guimarães Rosa, falando-se e falando sertanejo, não visita, nem revisita, um continente folclórico em vias de extinção ou marginalização no oceano de uma língua de uso comum, na aparência mais vocacional para a universalidade ou o comércio com o mundo. Guimarães Rosa desce ao porão do Brasil como língua, descobre-a, e não por acaso, naquelas Minas sem as quais o Brasil como veio a existir nunca se teria feito nação. Nessa descida atravessa as camadas de fala, os tempos de uma língua que se reinventa (ou que ele pode recriar sem fim) para contar histórias de um passado aparentemente morto - e que é simplesmente a língua portuguesa, sem sujeito e com todos os sujeitos, tal como um Cristo descendo ao nosso limbo-língua onde as canções de amigo, Amadis, Fernão Lopes, Vieira ou todos os criadores do próprio Brasil esperassem a sua vinda para começar uma estória que não vem na história portuguesa que a transcende. (LOURENÇO, 2001, p. 218)

A “criação do Brasil” dá-se, portanto, com a língua em suas várias camadas, uma língua em comum que une, afinal, brasileiros e portugueses, porque evoca todos os que escreveram nessa língua. Uma estória que não vem da história portuguesa, mas que se comunica com ela por meio de seus grandes escritores e dos vários modos como a língua portuguesa foi usada para expressar a comunicação literária. O estranhamento que a literatura de Rosa causa se estabelece, exatamente por conta desse resgate, através da ideia de que um texto literário não está preso a um período específico que a prosa de Vieira, por exemplo, ainda continua sendo lida e refletida, transferindo o passado para o presente.

Aleida Assmann, em Espaços da recordação, cita Stephen Greenblat, um estudioso da obra de Shakespeare, que explicita por que estudar escritores de outra época: "Comecei com o desejo de conversar com os mortos”. (ASMANN, 2011, p. 193). Eduardo Lourenço, ao usar a imagem de um Cristo que desce ao limbo para "resgatar" as línguas das cantigas de amigo, de Amadis, Fernão Lopes e Vieira, cria uma metáfora de como Rosa, ao construir sua obra, continua a conversa com os mortos numa espécie de movimento que é o de uma linguagem resgatada e reinventada. Essa pode ser a fonte do estranhamento: Guimarães Rosa parecia não estar preocupado com estilo, época ou tema literário. Seguindo o que Machado evidencia em "Instinto de Nacionalidade", o tema pode ser qualquer um, desde que bem conduzido por seu escritor. A liberdade literária se dá em prol de uma preocupação menor com estilo e época e aprofunda-se a partir de obras e autores que representam sua época, mas que seguem além - afinal, a força comunicativa de sua obra é atemporal. 
Rosa conta o sertão. Seu livro mais conhecido é um grande monólogo. E, no entanto, não é por ser um sertanejo de pouca cultura que sua fala limitar-se-á ao modo tacanho, já tão marcado na literatura. Por meio de Riobaldo, conceitos sobre o amor, a guerra, o aprendizado, a mulher e tantos outros se revelarão, pois a linguagem que ele usa está entranhada na alma através de séculos de literatura. É uma língua que se concentra sobre si mesma e estabelece uma altura construtiva que jamais havia sido registrada na literatura brasileira até então. O ficcional se amplia em significado, pois, antes de tudo, é a linguagem que se propõe também uma ficção.

Willi Bolle (2004), em seu estudo a respeito do Grande sertão: veredas, ressalta o uso da linguagem por parte de Rosa como uma grande invenção, e que por isso ele é ao mesmo tempo um revolucionário e um reacionário do idioma. E é por meio dessa linguagem que o crítico alemão acredita que acontece a inserção de um discurso a respeito do que é o Brasil:

(...) não se trata somente de questões estritamente literárias ou estéticas, mas de um projeto de formação social, com a inclusão das camadas populares. Através de seu alter ego Riobaldo, que se movimenta no meio das falas do povo, o escritor está em contato com a oficina onde se forja a língua. (BOLLE, 2004, 402)

E para que serve essa língua? Serve para contar estórias, serve contar o não contável, aquilo que parece impossível ao homem, mas que se dá no espaço da ficção, palco possível para tudo. Talvez, daí, o silêncio do ouvinte de Riobaldo, diante de uma fala que transcende o simples contar:

Essa estória é simplesmente a nossa história ainda por vir e por fazer, mas não a de um Quinto Império, imaginado para compensar o império perdido ou a perder. Como quem brinca - a sua ficção foi e é o mais lúdico dos jogos que a nossa língua inventou para não estar só no mundo -, Guimarães Rosa (que tanta gente da nossa fala imaginou ilegível, quando ele estava lendo com mediana clare$z a$ na própria fonte donde nos fala nossa língua) pôs ou repôs não apenas o imaginário brasileiro, mas também o lusófono, na hora zero, alfa e ômega de uma história que só existe porque alguém a sonha e a conta aos outros. Mesmo ausente, como o ouvinte silencioso a quem Riobaldo conta sem saber a quem aquilo que nunca poderá ser imitado. E é para contar o não contável que a ficção existe. (LOURENÇO, 2001, p. 218-219) 
O terceiro sertão, ou o terceiro Brasil, dá-se a partir de uma língua que se reinventa, que está encenada num passado que é passado e que é presente. Na modernidade da cidade, no mudismo do sertão que é sertão porque está além do espaço - é condição. Para Lourenço, como para grande parte da crítica a respeito da obra de Rosa, uma das principais características do autor é a universalidade. O crítico português aponta para o fato de essa universalidade não estar relacionada com a questão da geografia brasileira - "Universalidade que nem sequer é metaforicamente a da continentalidade do Brasil como geografia ou história - mas Gerais - Mundo, por que tudo é sertão" (LOURENÇO, 2001, 212) -, mas com todas as visões que podem ser criadas para o espaço brasileiro.

Bolle defende a ideia de que a obra de Rosa é uma reescritura crítica de Os sertões de Euclides da Cunha. Desse modo, Grande sertão: veredas se filiaria aos textos que tradicionalmente são considerados "retratos do país". O texto do autor mineiro transgrediria a obra de Euclides ao dar voz aos marginalizados, ao criar a possibilidade de que o próprio jagunço relatasse sua vida, seu modo de ser e, com isso, um Brasil mais "genuíno", por meio da linguagem:

No projeto de Guimarães Rosa de reiventar o português do Brasil, o ato criador individual ("Esta língua atualmente deve ser pessoal, uma criação do próprio autor") é tão importante quanto a tarefa coletiva: "O brasileiro (...) ainda deve criar a sua própria língua". Com essa combinação da poética individual e coletiva, o projeto de Guimarães Rosa difere radicalmente da representação do país por parte de Euclides. Este autor, apesar do imenso e rebuscado repertório verbal e da estilização poética, não foge ao hábito arraigado dos letrados brasileiros de valorizar a erudição em detrimento da linguagem do povo. Em Guimarães Rosa, pelo contrário, a fala dos sertanejos é um componente fundamental do seu retrato do Brasil. (BOLLE, 2004, p. 404)

O romance de Rosa é, nesse sentido, uma fala "de dentro", já que toda a estilização da linguagem acontece para revelar não só a vida de um ex-jagunço, mas toda uma classe social. Por meio de sua história, Riobaldo desvela as estruturas sociais vistas por quem as vive. Bolle compara o romance rosiano aos retratos do $\mathrm{Brasil}^{4}$, mas ressalta que mesmo sendo escrito por um intelectual, a visão do Brasil que apresenta é a do homem comum, muitas vezes marginalizado.

4 Como os textos de Gilberto Freire (Casa grande e sensala), Sérgio Buarque de Holanda (Raízes do Brasil) e Caio Prado (Formação do Brasil contemporâneo). 
Ao contrário de Euclides da Cunha, ou dos romancistas de 30 , Rosa elabora um discurso sobre o país por meio de uma história individual, que aparentemente não se pretende um discurso acerca de toda a nação, mas de uma trajetória de filho bastardo e marginalizado, passando a chefe de jagunços e para tornar-se finalmente latifundiário; o texto é permeado por questões religiosas e por uma história de amor. Bolle acredita que mais que um romance de formação tradicional, em que se destaca a trajetória de um indivíduo, Riobaldo representa o que chama de "romance de formação do país" (2004, p. 378).

Como "jagunço letrado" 5 , Riobaldo consegue se colocar entre diferentes meios sociais. Ele acaba por realizar "um complexo trabalho de mediação entre os diferentes discursos sociais" (2004, p. 382).

Lorenço aponta que Grande sertão: veredas ainda traz em sua composição o duplo, já que não ignora a tragicidade que compõe a obra de Euclides, mas insere um "optimismo transcendente". Com isso, o romance é epopéia e alegoria, o que possibilita que sua abordagem sobre o sertão e o sertanejo seja mais humana (Lourenço pondera também a respeito da presença de questões sobre o bem e o mal e o sentido da vida, além, é claro, da história de amor).

Porém, o romance de Rosa (bem como grande parte de sua obra) apresenta como característica primordial, como sua "mônada de Leibniz", o uso da linguagem. Lourenço afirma que a maneira como Rosa utiliza e recria a língua - ou na verdade, "desce ao porão do Brasil como língua", afinal trata-se de, como o próprio autor afirmou, um "reacionário da língua" e não um "revolucionário". É a conquista que os modernos de 22 quiseram empreender. Mesmo que de um modo diferente, a intuição de Lourenço acaba por se mostrar semelhante à de Bolle.

Seu texto apresenta uma construção de Brasil original a partir do trabalho que trava com a linguagem, ao mesmo tempo em que constrói um espaço que faz parte da nacionalidade brasileira desde Os sertões de Euclides da Cunha; no entanto, dá a essa nacionalidade, a esse brasileiro, sua condição de ser como tal. Não se trata de uma construção criada com e para o olhar do citadino brasileiro, que muitas vezes olha para o seu igual com o mesmo olhar do europeu, mas de uma construção, mesmo que ficcional, capaz de expressar genuinamente a condição do brasileiro/sertanejo.

Nas obras de Rosa há o mal, a violência assumida, a religiosidade - são os descompassos do Brasil moderno, que necessita "matar o pai" para poder se assumir; eis o processo de construção e de compreen-

5 Esse termo foi cunhado no estudo de Walnice Nogueira Galvão intitulado As formas do falso (1972). 
são de sua história. É por meio da linguagem que cria para suas estórias que ela conquista sua autonomia. É a partir do seu "Nonada" que a literatura brasileira, mesmo que em um movimento de negação, conquista o projeto modernista nacional.

\section{ConClusÃo}

Reflexões acerca da formação da literatura brasileira sempre tiveram como pano de fundo o questionamento sobre o colonizador e a figura de Portugal como pai. Eduardo Lourenço percebe essa postura da crítica e da literatura brasileira ao tentar se firmar como um país independente em todos os sentidos. No Romantismo criou-se uma situação crucial para essa manobra de independência. As falhas, no entanto, são sentidas e prontamente apontadas a partir das reflexões de Machado de Assis sobre o fazer literário. Contemporâneo de Machado, Euclides da Cunha dá à nação uma obra que reúne o desconhecido e o grotesco, fazendo com que a manobra do período Romântico e Realista se manifestasse apenas como parte da representação da literatura brasileira. Mais tarde, com a Semana de 1922, os moços de São Paulo tomam as rédeas para estabelecer o critério de como a literatura e a arte deveriam ser pensadas. Eduardo Lourenço percebe a suma importância desse momento, porém estabelece ele está longe de ser reconhecido como mito fundador da tão almejada independência da literatura brasileira.

A reflexão de Lourenço debruça-se em um momento mais tardio, quando Guimarães Rosa lançará ao mundo o Grande Sertão: Veredas. Se Euclides inaugurou esse caminho "para dentro" de um país desconhecido, Rosa se apoderou com maestria da língua, dando voz e vez ao jagunço, falador e contador de histórias, o homem que é local e universal, o homem que, afinal, se comunica como seus iguais e com seus diferentes. Lourenço percebe nessa obra uma retomada precisa da língua portuguesa como estabelecedora de uma tão sonhada unidade, pois é a unidade do homem que se comunica, independente de distâncias, épocas e línguas. Em um outro ensaio, intitulado "Errância e busca num imaginário lusófono", também pertencente à obra $A$ nau de Ícaro, Eduardo Lourenço reflete sobre o tema da busca na produção ficcional. Essa busca indefinida, presente na produção ficcional de todos os tempos, também se presentifica no Grande Sertão: Veredas; o sertanejo se reconstrói como um êmulo do cavaleiro medieval, aquele que busca o absoluto. Arcaísmo e modernidade se mesclam no tema dessa busca 
e Lourenço aproxima a imensidão do sertão - que é busca externa e interna - ao mar português de Pessoa:

o paradigma do andante cavaleiro - se deixamos de lado Amadis, flor que ninguém sabe de que terra nos chegou - já encontrara na nossa comum e reinventada língua a mais fabulosa das suas versões, ao mesmo tempo contemporânea e arcaica: a de Grande sertão - veredas. Sertão, o mundo, veredas os caminhos que por serem terrestres não são menos indefinidos e misteriosos que do arquétipo pessoano "mar português" (LOURENÇO, 2001, p. 113)

Confirma-se que a tão sonhada independência dá-se afinal pela língua, que não se divorcia de suas origens, mas reinventa-se. Indefinido é o sertão, indefinido é o mar. A construção imagética dada pela língua é quem decreta o caminho dessa busca, seja portuguesa, seja brasileira.

\section{REFERÊNCIAS}

ASSIS, Machado de. Instinto de nacionalidade. In: . Crítica, notícia da atual literatura brasileira. São Paulo: Agir, 1959. p. 28-34

ASSMANN, Aleida. Espaços da recordação: formas e transformações da memória cultural. Campinas: Editora da Unicamp, 2011.

BOLLE, Willi. grandesertão.br: o romance de formação do Brasil. São Paulo: Duas Cidades; Editora 34, 2004.

CANDIDO, Antonio. Formação da literatura brasileira. Rio de Janeiro: Ouro sobre Azul, 2012. COUTINHO, Afrânio. Conceito de literatura brasileira. Petrópolis: Vozes, 2008.

CUNHA, Euclides da. Os sertões. Rio de Janeiro: Publifolha, 2000. 
POLESE. E. S., KOEHLER, J. Eduardo Lourenço E a terceira margem do Brasil: um olhar ...

GALVÃo, Walnice Nogueira. Polifonia e paixão. In: CUNHA, Euclides da. Obra Completa: volume 1. Rio de Janeiro, Nova Aguilar, 2009.

LOURENÇO, Eduardo. A nau de Ícaro. São Paulo: Companhia das Letras, 2001.

ROSA, João Guimarães. Grande sertão: veredas. Rio de Janeiro: Nova Fronteira, 1986.

Submetido em: 01/08/2014

Aceito em: 27/09/2014 